PRAMANA

(C) Indian Academy of Sciences

Vol. 81 , No. 2

- journal of

August 2013

physics

p. 365

\title{
Erratum to: A simplistic pedagogical formulation of a thermal speed distribution using a relativistic framework
}

\author{
ASHMEET SINGH \\ Department of Physics, Indian Institute of Technology Roorkee, Roorkee 247 667, India \\ E-mail: ashmtuph@iitr.ernet.in
}

Pramana - J. Phys. 81(1), 143-156 (2013)

Equation (9) in the original publication of this article (DOI: 10.1007/s12043-013-0548-x) is unfortunately wrong. $\mathrm{d} \tau / \mathrm{d} t$ should have been $\mathrm{d} t / \mathrm{d} \tau$. The correct equation is displayed here. The author regrets this error.

$$
\frac{\mathrm{d} t}{\mathrm{~d} \tau}=\left(1-\frac{v^{2}}{c^{2}}\right)^{-1 / 2}=\gamma
$$

